\title{
Monensin Induces PC-3 Prostate Cancer Cell Apoptosis via ROS Production and $\mathrm{Ca}^{2+}$ Homeostasis Disruption
}

\author{
SANG-HUN KIM ${ }^{1 *}$, KWANG-YOUN KIM ${ }^{2 *}$, SUN-NYOUNG YU ${ }^{1}$, SUL-GI PARK ${ }^{1}$, \\ HAK-SUN YU ${ }^{3,4}$, YOUNG-KYO SEO ${ }^{5}$ and SOON-CHEOL AHN ${ }^{1,4}$ \\ Departments of ${ }^{1}$ Microbiology and Immunology, and ${ }^{3}$ Parasitology, and \\ ${ }^{4}$ Immunoregulatory Therapeutics Group in Brain Busan 21 Project, \\ Pusan National University School of Medicine, Yangsan, Republic of Korea; \\ ${ }^{2}$ Department of Herbal Formula, Medical Research Center (MRC-GHF), \\ College of Oriental Medicine, Daegu Haany University, Gyeongsan, Republic of Korea; \\ ${ }^{5}$ School of Life Sciences, Ulsan National Institute of Science and Technology, Ulsan, Republic of Korea
}

\begin{abstract}
Background: Monensin is a carboxyl polyether ionophore that potently inhibits the growth of various cancer cells. Recently, the anticancer effects of monensin have been recognized based on its ability to induce apoptosis in cancer cells. However, anticancer effect of monensin and its mechanism of action have yet to be investigated, especially against human prostate cancer cells. Materials and Methods: Cell viability assay, western blot, cell-cycle arrest, annexin V/propidium iodide assay, reactive oxygen species (ROS) production and intracellular $\mathrm{Ca}^{2+}$ flux were assayed. Results: In this study, monensin significantly inhibited cell viability in a dose-dependent manner in prostate cell lines. Moreover, cell growth inhibition by monensin induced $G_{1}$ phase cellcycle arrest and apoptosis via regulation of cell cycle-and apoptosis-related proteins in $\mathrm{PC}-3$ cells. In addition, monensin induced the production of ROS and the disruption of $\mathrm{Ca}^{2+}$ homeostasis, that was restored by diphenyleneiodonium, a mitochondrial ROS inhibitor and verapamil, a $\mathrm{Ca}^{2+}$ channel blocker, respectively, as confirmed by pro-caspase-3 activation and poly ADP ribose polymerase cleavage. Conclusion: Monensin induces cell-cycle arrest and apoptosis through regulation of cell cycle- and apoptosis-
\end{abstract}

*These Authors contributed equally to this study.

Correspondence to: Professor Soon-Cheol Ahn, Department of Microbiology and Immunology, Pusan National University School of Medicine, Yangsan 50612, Republic of Korea. Tel: +82 515108092, Fax: +82 553828090, e-mail: ahnsc@ pusan.ac.kr and Professor Young-Kyo Seo, School of Life Sciences, Ulsan National Institute of Science and Technology, Ulsan 44919, Republic of Korea. Tel: +82 522172626, Fax: +82 522172609, e-mail: ykseo@unist.ac.kr

Key Words: monensin, apoptosis, $\mathrm{ROS}$ production, $\mathrm{Ca}^{2+}$ homeostasis. related proteins, resulting in induction of mitochondrial ROSand $\mathrm{Ca}^{2+}$-dependent apoptosis, respectively.

Apoptosis, one of the chemotherapeutic strategies, is an evolutionary-conserved and highly regulated process that involves activation of a series of molecular events $(1,2)$ Several reports have shown that apoptosis is induced via various extracellular stresses, including reactive oxygen species (ROS) (3). ROS play vital roles in apoptosis and some other cellular events $(4,5)$. Furthermore, the regulation of ROS production has been used to investigate the maintenance of cell growth and differentiation, and homeostasis (6). Prolonged and irreversible ROS accumulation causes oxidative stress via affecting various cellular signaling pathways including apoptosis induction (7). Apoptosis induction is related to ROS generation and intracellular calcium flux (8). ROS influence mitochondrial function and mediate intracellular calcium levels, leading to the activation of pro-apoptotic proteins (9). Our previous report showed that both ROS and the calcium contribute to mitochondrial dysfunction, finally inducing apoptosis $(10,11)$.

Monensin is a typical carboxylic ionophore produced by Streptomyces cinnamonensis and mediates $\mathrm{Na}^{+} / \mathrm{H}^{+}$exchange in biological membranes (12). Polyether ionophore antibiotics are able to form lipophilic complexes with monovalent cations and hence can cause cation imbalances, which are known to produce different biochemical and histological alterations (13). Polyether ionophore antibiotics such as monensin, salinomycin, narasin and lasalocid A, have the ability to induce apoptosis and cause growth inhibition in diverse types of cancer cells (14-16). Several reports also indicated that monensin and salinomycin were able to overcome multidrug resistance in cancer cells and specifically killed human cancer stem cells $(16,17)$. Therefore, polyether ionophores are currently a potential 
therapeutic candidate for the prevention and treatment of cancer $(13,18)$. However, the anticancer activities of monensin on human prostate cancer cells are not fully understood. In the present study, in order to investigate the effect of monensin on prostate cancer, PC-3 cells were treated with monensin and apoptosis and cell cycle regulation were examined. The underlying events relevant to apoptosis were also studied in detail, including the production of ROS and failure of $\mathrm{Ca}^{2+}$ homeostasis.

\section{Materials and Methods}

Reagents and antibodies. 3-(4,5-Dimethyl-thiazol-2-yl)-2,5diphenyl-etrazolium bromide (MTT), propidium iodide (PI), 2'-7'dichlorodihydrofluorescein diacetate (DCFH-DA), 3,3dihexyloxacarbocyanine $\left(\mathrm{DiOC}_{6}\right)$, dehydroxytestosterone (DHT), 4(6-acetoxymethoxy-2,7-dichloro-3-oxo-9-xanthenyl)-4'-methyl-2,2' (ethylenedioxy) dianiline- $N, N, N^{\prime}, N^{\prime}$-tetraacetic acid tetrakis (acetoxymethyl) ester (Fluo-3/AM), diphenyleneiodonium (DPI), $\mathrm{N}$ acetyl-L-cysteine (NAC), 4-hydroxy-2,2,6,6-tetramethylpiperidine 1-oxyl (TEMPOL), rottlerin and apocynin were purchased from Sigma Chemical Co. (St. Louis, MO, USA). Annexin V- fluorescein isothiocyanate (FITC) detection kit was obtained from BD Biosciences (San Jose, CA, USA). The ECL western blotting kit was purchased from Amersham (Arlington Heights, IL, USA). Antibodies for B-cell lymphoma 2 (BCL2), BCL-2-like protein 4 (BAX), cyclin-dependent kinase 2 (CDK2), CDK6, cyclin D1, cyclin E and poly ADP ribose polymerase (PARP) were purchased from Santa Cruz Biotechnology (Santa Cruz, CA, USA). Antibodies to caspase-3 and cyclin A were purchased from Cell Signaling Technology (Beverly, MS, USA). CDK4 antibody was purchased from Stressgen (Glanford Ave, Victoria, BC, Canada).

Cell lines and culture. Human prostate cancer cell line, androgenindependent PC-3 cells and androgen-dependent LNCaP cells were obtained from the American Type Culture Collection (ATCC, Manassas, VA, USA). These cells were maintained and cultured in Dulbecco's modified Eagle's medium (DMEM) and RPMI supplemented with $10 \%$ fetal bovine serum (FBS), 100 units $/ \mathrm{ml}$ of penicillin and $100 \mu \mathrm{g} / \mathrm{ml}$ of streptomycin (all from WelGENE Inc., Daegu, Korea) (WelGENE Inc.), respectively. Cells were cultured at $37^{\circ} \mathrm{C}$ in a humidified atmosphere with $5 \% \mathrm{CO}_{2}$. The cells were diluted in appropriate medium before each experiment.

MTT assay. PC- 3 cells and LNCaP cells $\left(1 \times 10^{4}\right.$ cells per well) were seeded in 48-well plates and were treated with monensin $(0.15-$ $1,500 \mathrm{nM}$ ) for $24 \mathrm{~h}$ in duplicate. After treatment, $0.5 \mathrm{mg} / \mathrm{ml}$ of MTT solution were added to each well, and plates were incubated for another $4 \mathrm{~h}$. The MTT-formazan produced by viable cells was then dissolved in dimethyl sulfoxide (DMSO). Colorimetric analysis was performed at $540 \mathrm{~nm}$ using an ELISA reader (VERSA max $_{\text {microplate }}$ reader, Molecular Devices, Toronto, Canada).

Cell-cycle analysis. Cell-cycle distribution was determined by staining DNA with PI. Briefly, cells $\left(1 \times 10^{5}\right.$ cells per well $)$ were incubated with or without monensin for $24 \mathrm{~h}$. The cells were then washed twice with cold phosphate-buffered saline (PBS), trypsinized and centrifuged at $4^{\circ} \mathrm{C}$ for $4 \mathrm{~min}$. The cell pellet was then fixed in $70 \%$ ice-cold ( $\mathrm{vol} / \mathrm{vol}$ ) ethanol for $18 \mathrm{~h}$ at $-20^{\circ} \mathrm{C}$.
Fixed cells were washed once with PBS and resuspended in RNase A/PBS $(200 \mu \mathrm{g} / \mathrm{ml})$ at $37^{\circ} \mathrm{C}$ for $30 \mathrm{~min}$. Next, DNA content per cell was evaluated by flow cytometry (Becton Dickinson Co., Franklin Lakes, NJ, USA) after staining cells with PI $(1 \mathrm{mg} / \mathrm{ml})$ at room temperature for $5 \mathrm{~min}$. Data collection and analysis of the cellcycle distribution were performed using Cell Quest software (Becton Dickinson Co.).

Annexin V/PI assay. Apoptotic cells were observed by using Annexin V-FITC detection kit (BD Biosciences) and by flow cytometry. PC-3 cells were cultured in 6-well plates at a density of $1 \times 10^{4}$ cells per well. The cells were refreshed with new medium when $60 \%$ confluent and then exposed to monensin for $24 \mathrm{~h}$. After incubation, trypsinized floating and adherent cells were pooled and centrifuged. Harvested cells were rinsed with PBS twice, mixed in $1 \mathrm{X}$ binding buffer $(100 \mu \mathrm{l})$ and incubated with annexin V/PI double staining solution at room temperature for $20 \mathrm{~min}$. The stained cells were analyzed by flow cytometry (Becton Dickinson Co.) and the percentage of apoptotic cells was calculated using Cell Quest software (Becton Dickinson Co.).

Measurement of intracellular ROS production. Intracellular ROS production was measured using DCFH-DA fluorescent dye. PC-3 cells were cultured in 6-well plates at a density of $1 \times 10^{4}$ cells per well. Cells treated with monensin were incubated with DCFH-DA $(10 \mu \mathrm{M})$ at $37^{\circ} \mathrm{C}$ for $20 \mathrm{~min}$, and then washed twice with PBS. For each experiment, the cells were analyzed for fluorescence using flow cytometry.

Analysis of intracellular $\mathrm{Ca}^{2+}$ concentration. Changes in intracellular $\mathrm{Ca}^{2+}$ concentration were determined by using the fluorescent dye Fluo-3/AM. PC-3 cells were cultured in 6-well plates at a density of $1 \times 10^{4}$ cells per well. Cells were then centrifuged and washed twice with PBS. The cells were incubated with $5 \mu \mathrm{M}$ Fluo-3/AM at $37^{\circ} \mathrm{C}$ for $20 \mathrm{~min}$. Then the cells were washed and subjected to flow cytometric analysis.

Western blot analysis. Cells were plated in 6-well plates at a density of $1 \times 10^{5}$ cells per well and incubated with monensin for $24 \mathrm{~h}$. The cells were washed with PBS and total cells were trypsinized, collected and lysed in a lysis buffer [ $150 \mathrm{mM} \mathrm{NaCl}, 10 \mathrm{mM}$ Tris ( $\mathrm{pH} 7.4), 5$ mM EDTA (pH 8.0), 1\% Triton X-100, 1 mM phenylmethylsulfonyl fluoride, $20 \mathrm{mg} / \mathrm{ml}$ aprotinin, $50 \mu \mathrm{g} / \mathrm{ml}$ leupeptin, $1 \mathrm{mM}$ benzamidine, $1 \mathrm{mg} / \mathrm{ml}$ pepstatin]. Fifty micrograms of proteins determined by the bicinchoninic acid method were electrophoretically separated using $12-15 \%$ sodium dodecyl sulfate-polyacrylamide gel electrophoresis (SDS-PAGE) gel and transferred to polyvinylidence fluofide membrane. After blocking with TBS-T buffer [20 mM Tris ( $\mathrm{pH} 7.4)$, $150 \mathrm{mM} \mathrm{NaCl}, 0.1 \%$ Tween 20] containing 5\% skim milk, the membranes were incubated with primary and secondary antibodies as given in the Materials and Methods. The membranes were then washed with TBS-T buffer and visualized with ECL western blotting detection reagent (American International, Amersharm, UK). The density of bands was determined with a fluorescence scanner (LAS 3000; Fuji Film, Tokyo, Japan) and analyzed with Multi Gauge V3.0 software (Fuji Film).

Statistical analysis. Experiments were repeated at least three times with consistent results. Unless otherwise stated, data are expressed as the mean $\pm \mathrm{SD}$. ANOVA was used to compare experimental groups 
$\mathbf{A}$

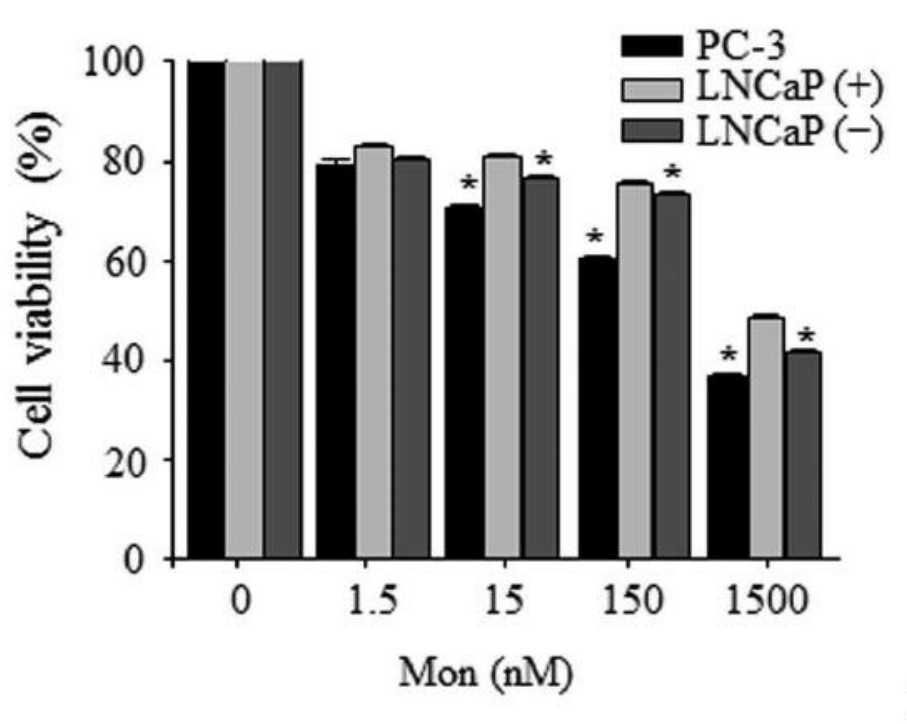

B

C
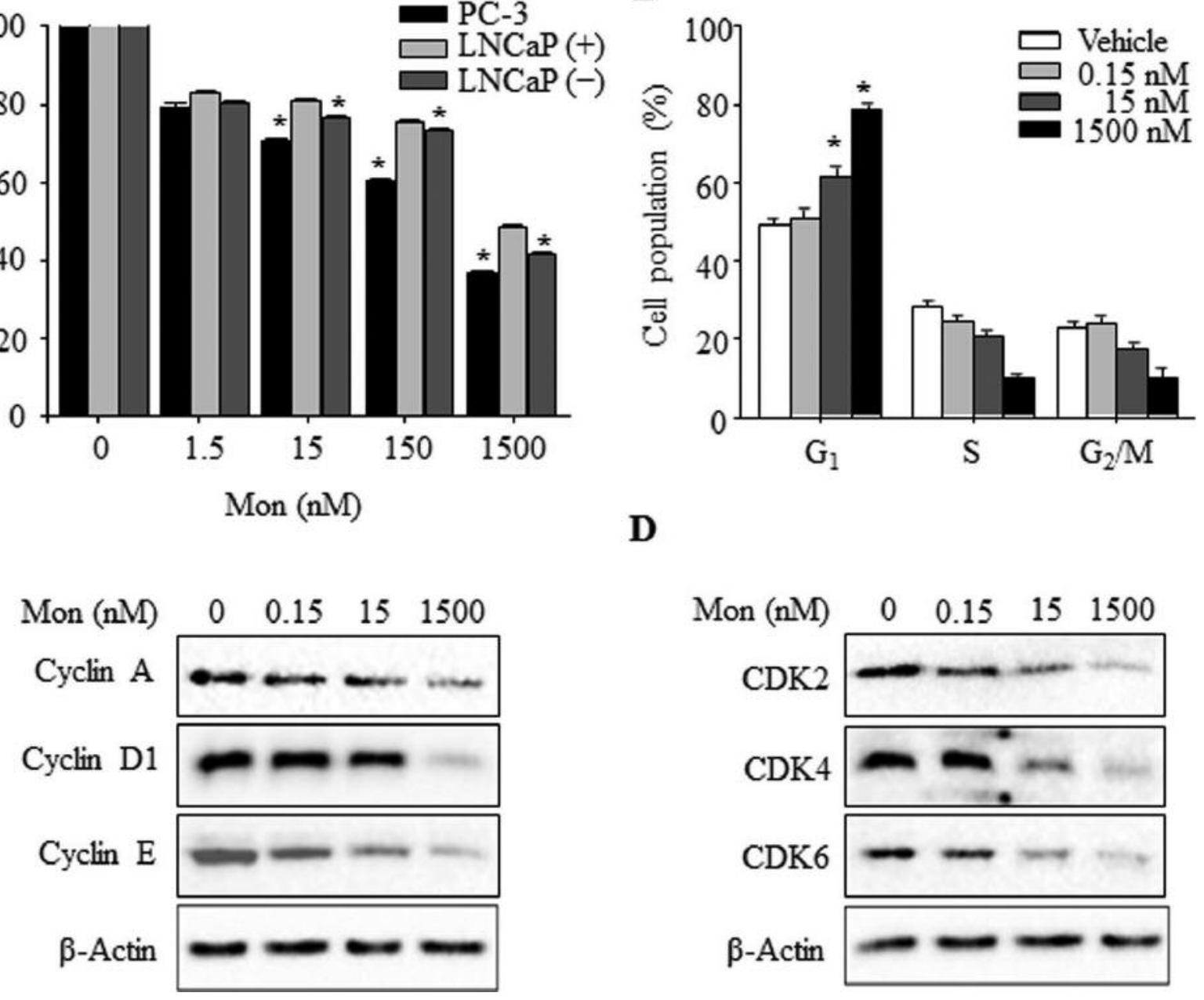

D

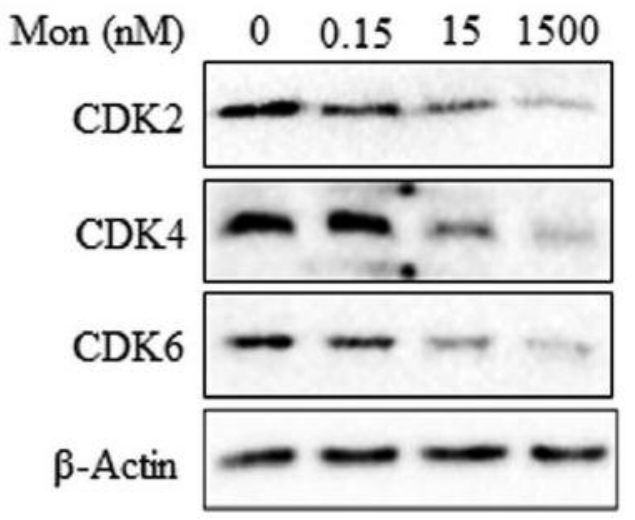

Figure 1. Monensin inhibits cell growth and $G_{1}$ phase cell-cycle progression in prostate cancer cells. A: Cell viability. PC-3 and LNCaP cells were treated with the indicated concentrations of monensin for $24 \mathrm{~h}$. LNCaP cells were cultured with or without dehydroxytestosterone (DHT) $(0.1 \mu M)$. Cell viability was determined by a 3-(4,5-dimethyl-thiazol-2-yl)-2,5-diphenyl-tetrazolium bromide (MTT) assay. B: $G_{1}$ phase cell-cycle arrest. Cellcycle distribution was determined by staining DNA with propidium iodide for 20 min followed by washing in phosphate-buffered saline and fixing in $70 \%$ ethanol. The percentage of cells in the different phases of the cell cycle was measured with a flow cytometry. C, D: Immunoblots of cyclins and cyclin-dependent kinases $(C D K)$ s. Cyclin and CDK expression in total cell lysates were subjected to sodium dodecyl sulfate-polyacrylamide gel electrophoresis for western blot analysis. $\beta$-Actin was used as a loading control. Data are the mean $\pm S D\left(n=3\right.$ in each group). ${ }^{*} p<0.05$ vs. the control.

to controls, while comparisons between multiple groups were made using Tukey's multiple comparison test. Statistical significance was determined as a $p$-value less than 0.05 .

\section{Results}

Monensin suppresses the growth of prostate cancer cells. To explore the anticancer effects of monensin on prostate cancer, we first confirmed effects on cell viability of androgen-independent PC-3 and androgen-dependent LNCaP cells by MTT after treatment with different concentrations (0-1,500 $\mathrm{nM})$ of monensin for $24 \mathrm{~h}$. Monensin inhibited cell growth dose-dependently in both PC-3 and LNCaP cells (Figure 1A). Furthermore, LNCaP cell viability was higher when treated with $0.1 \mu \mathrm{M}$ DHT than without DHT. Monesin also significantly inhibited the viability of PC-3 cells more than LNCaP cells. In addition, monensin caused the number of non-adherent and detached cells to increase and reduced cell volume (data not shown). Thus, hormone-independent PC-3 cells had higher susceptibility to monesin than hormone-dependent LNCaP cells. Therefore, we focused on the mechanism associated with the monensin-inhibited cell viability of the PC-3 cells. 
A
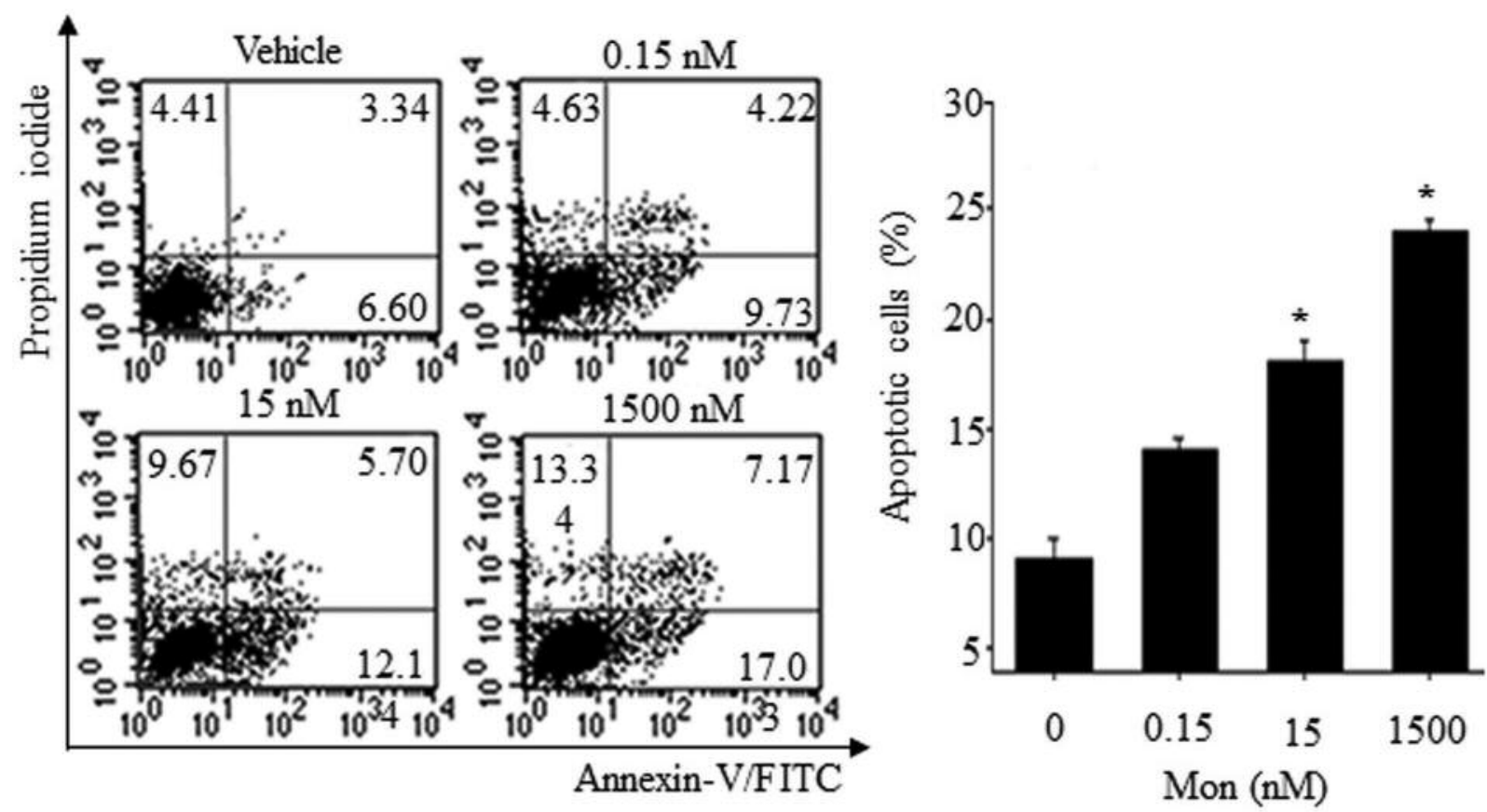

B

C
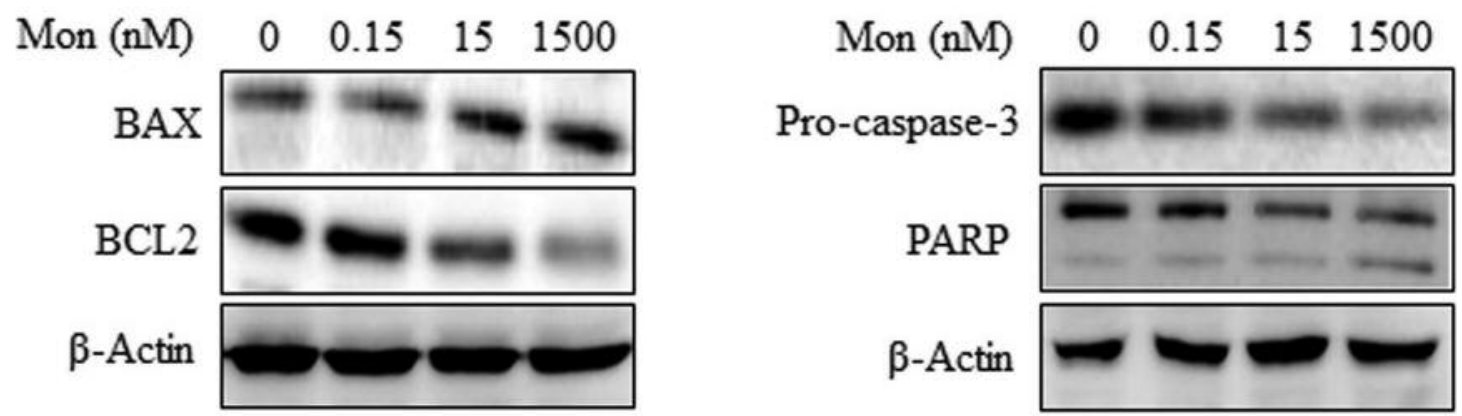

Figure 2. Monensin induces apoptosis of PC-3 cells. A: Apoptosis induction. PC-3 cells were treated with the indicated concentrations of monensin for $24 \mathrm{~h}$ and apoptosis was determined by flow cytometry. B, C: Immunoblots of apoptosis-related proteins. B-cell lymphoma 2 (BCL2), BCL2-like protein $4(B A X)$, pro-caspase-3 and poly (ADP-ribose) polymerase (PARP) expression in total cell lysates were subjected to sodium dodecyl sulfatepolyacrylamide gel electrophoresis for western blot analysis. $\beta$-Actin was used as a loading control. Data are the mean $\pm S D(n=3$ in each group). $* p<0.05$ vs. the control.

Monensin induces $G_{1}$ cell-cycle arrest by down-regulating cyclins and CDKs in PC-3 cells. To examine whether the inhibition of cell growth by monensin was associated with cell-cycle arrest in PC-3 cells, we evaluated cell-cycle progression by flow cytometry using PI staining. Monensin significantly increased the $G_{1}$ phase cell numbers in a dosedependent manner, accompanied by a decrease in the $\mathrm{S}$ phase cell number (Figure 1B). Furthermore, monensin reduced the levels of $\mathrm{G}_{1} / \mathrm{S}$ phase transition-associated proteins, including cyclin A, cyclin D1, cyclin E, CDK2, CDK4 and CDK6, in a dose-dependent manner (Figure $1 \mathrm{C}$ and D). These results show that monensin inhibits cellular proliferation of PC-3 cells via $\mathrm{G}_{1}$ arrest, similar to previous reports (19).

Monensin induces apoptosis of PC-3 cells. We further determined whether monensin-induced cell growth inhibition 
was involved in apoptosis; we confirmed the apoptotic characteristics by flow cytometry using annexin V/PI staining. Late or early apoptotic cells were markedly increased by monensin in a dose-dependent fashion (Figure 2A). The apoptotic cells reached to $17.84 \%$ and $24.20 \%$ and necrotic cells accounted for $9.67 \%$ and $13.34 \%$ at 15 and $1,500 \mathrm{nM}$, respectively. Furthermore, in order to evaluate the mechanism of monesin-induced apoptosis, we determined the expression of main apoptosis-related proteins, BAX, BCL2, PARP and pro-caspase-3 by western blot analysis. Monensin increased BAX expression but reduced BCL2 expression, consequently the BAX/BCL2 ratio was increased in a dose-dependent manner (Figure 2B). Monensin also reduced pro-caspase- 3 expression, finally leading to the induction of apoptosis by monensin, because caspase- 3 plays an essential role in apoptosis (Figure 2C). Meanwhile, PARP, which serves as a hallmark of apoptosis, was cleaved into two bands by treatment with $1,500 \mathrm{nM}$ of monensin (Figure $2 \mathrm{C})$. These results suggest that monensin alters the protein levels of key members of the BCL2 family and caspase- 3 activation during apoptosis of PC-3 cells.

Monensin induces apoptosis through mitochondrial ROS production in PC-3 cells. Excess ROS production is the primary cause of mitochondrial damage and energy metabolism disorder, leading to apoptosis (6). In order to further investigate whether the apoptotic mechanism induced by monensin is due to an increase of the intracellular ROS level, we assessed the DCHF-DA fluorescence intensity in $1500 \mathrm{nM}$ monensin-treated PC-3 cells. ROS generation was gradually enhanced after $3 \mathrm{~h}$ monensin treatment compared with control cells, which was evidenced by an increase in the intensity of DCF fluorescence (Figure 3A). Next, in order to determine whether ROS production causes monensininduced apoptosis of PC-3 cells, we treated cells with various ROS inhibitors, including DPI, NAC, TEMPOL, rottlerin and apocynin. In monensin-treated PC-3 cells, DPI, an inhibitor of mitochondrial ROS, caused marked inhibition of ROS production, while other inhibitors including NAC, a non-specific ROS scavenger, TEMPOL, rottlerin, and apocynin did not affect the ROS level (Figure 3B). In addition, pre-treatment with DPI significantly abrogated monensin-induced apoptosis, as evidenced by the restoration of pro-caspase-3 expression and reduction of PARP cleavage (Figure 3C and D). Since DPI is a potent inhibitor of mitochondrial respiration in intact cells, these results implied that mitochondrial ROS production plays an important role in monensin-induced apoptosis of PC-3 cells.

Monensin induces apoptosis through homeostasis of intracellular $\mathrm{Ca}^{2+}$ flux but ROS-independent pathway in PC3 cells. Intracellular calcium is an important messenger molecule in apoptosis induction. In order to examine whether the change in intracellular $\mathrm{Ca}^{2+}$ concentration is associated with monensin-induced apoptosis, we performed staining with Fluo-3/AM fluorescence dye then flow cytometric analysis. Several reports showed that apoptosis is caused by increase of intracellular $\mathrm{Ca}^{2+}$ levels $(10,20)$ Our results showed that the number of Fluo-3/AM-negative cells increased to $30 \%$ after monensin treatment compared with untreated cells, reflecting a loss of $\mathrm{Ca}^{2+}$ (Figure 4A). This is consistent with a report that lower intracellular $\mathrm{Ca}^{2+}$ also promotes apoptosis (21). Moreover, the monesin-induced decrease in calcium level was significantly truncated by verapamil, an L-type calcium channel antagonist. As shown in Figure 4B and C, apoptotic cells decreased from 18 to $12 \%$, and were in the modulation of apoptosis-related proteins pro-caspase- 3 and PARP. Moreover, the decrease $\mathrm{Ca}^{2+}$ concentration was not blocked when the cells were pretreated with DPI (Figure 4D) and ROS production was not significantly affected when the cells were pretreated with verapamil (Figure 4E). Taken together, the result show intracellular $\mathrm{Ca}^{2+}$ participated in monensin-induced apoptosis but in an ROS-independent manner.

\section{Discussion}

Monensin, a carboxylic polyether ionophore, is widely used as a prophylactic or therapeutic anticoccidial and antibacterial agent $(12,22)$. Recently, polyether ionophores including menensin have been reported to induce growth inhibition or apoptosis in different human cancer cells and to reverse cancer multidrug resistance $(13,16,18)$. In the present study, we examined the possible mechanisms of monensin effects regarding the induction of apoptosis, cellcycle arrest, ROS production, and control of $\mathrm{Ca}^{2+}$ influx in PC-3 human prostate cancer cells. Since regulation of cellcycle progression is considered to be a potentially effective strategy for cancer cell growth, we first confirmed cell viability and cell-cycle arrest. We found that monensin inhibited cell proliferation by inducing cell-cycle arrest in a dose-dependent manner in PC-3 cells. Moreover, monensin arrested cells in $G_{1}$ phase and this was associated with a marked reduction of cyclins (cyclin A, D1 and E) and CDKs (CDK2, 4 and 6) in PC-3 cells. These results are consistent with salinomycin-induced $G_{1}$ phase cell-cycle arrest in prostate cancer cells as our previous data (23). These data suggest that $G_{1}$ phase arrest of cell-cycle progression provides an opportunity for cells to either undergo repair mechanisms or follow the apoptotic pathway.

Apoptosis is an important mode of cell death that occurs in response to a variety of cellular stresses $(24,25)$. Our data show that an apoptotic process was significantly increased in up to $20 \%$ of cells by monensin in a dose-dependent manner as comparedwith untreated control. Monensin differentially affected the levels of BCL2 and BAX in PC-3 cells, implying 
A

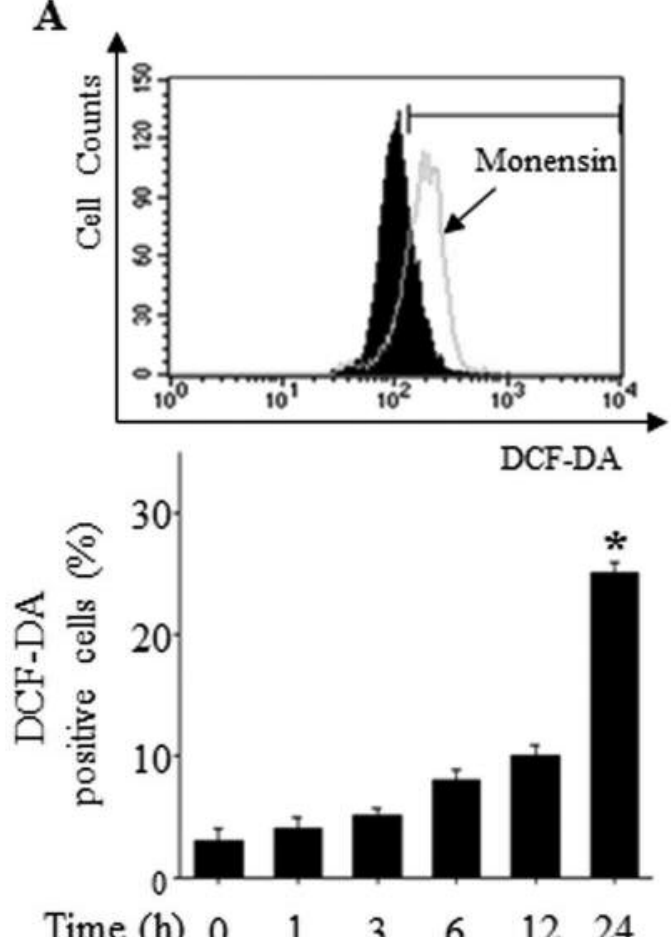

Time (h) $\begin{array}{llllll}0 & 1 & 3 & 6 & 12 & 24\end{array}$
B

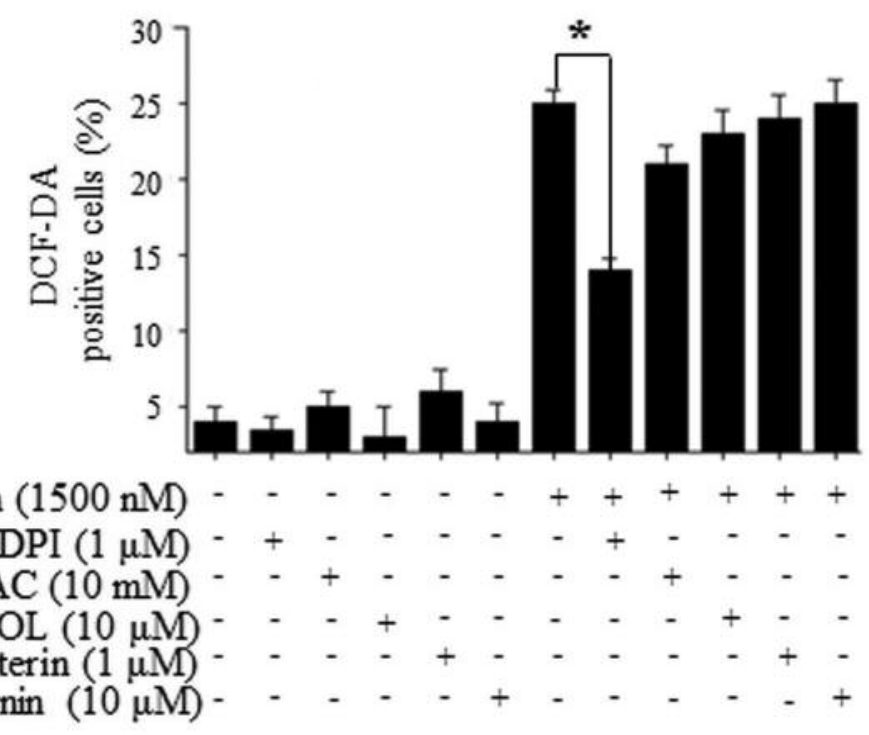

D

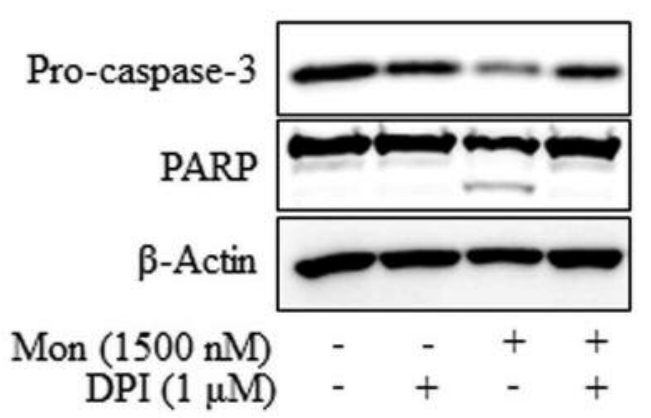

\section{Mon $(1500 \mathrm{nM}) \quad-\quad-\quad+\quad+$ $\mathrm{DPI}(1 \mu \mathrm{M})-+-+$}

Figure 3. Monensin induces reactive oxygen species (ROS)-dependent apoptosis of PC-3 cells. A: Intracellular ROS level. B: Effects of ROS inhibitors on ROS production. PC-3 cells were treated with 1,500 nM monensin for $24 \mathrm{~h}$ with or without prior $1 \mathrm{~h}$ incubation with ROS inhibitors diphenyleneiodonium (DPI), N-acetyl-L-cysteine (NAC), TEMPOL, rotterin and apocynin. ROS production was detected by 2'-7'dichlorodihydrofluorescein diacetate (DCF-DA) fluorescence intensity using flow cytometry. C: Effects of DPI on monensin-induced apoptosis. After annexin V/propidium iodide (PI) staining, apoptotic cells were analyzed by flow cytometry. D: Immunoblots of apoptosis-related proteins. PC3 cells were treated with 1,500 nM monensin for $24 \mathrm{~h}$ in the presence or absence of $1 \mu \mathrm{M}$ DPI. Pro-caspase-3 and poly (ADP-ribose) polymerase $(P A R P)$ expression in total cell lysates were subjected to sodium dodecyl-sulfate polyacrylamide gel electrophoresis for western blot analysis. $\beta$ Actin was used as a loading control. Data are the mean $\pm S D$ ( $n=3$ in each group). ${ }^{*} p<0.05$ vs. the control.

that BCL2 family proteins likely, in part, contribute to monensin-triggered apoptosis. Our data show that caspase-3 was activated and PARP protein was cleaved. Furthermore, mitochondria may overproduce ROS as a pro-apoptotic stimulus, which contributes to the apoptotic pathway $(26,27)$. Obviously, ROS production induces appearance of significant changes in apoptotic markers $(9,28)$. Consequently, we observed that monensin-induced ROS generation was 
$\mathbf{A}$
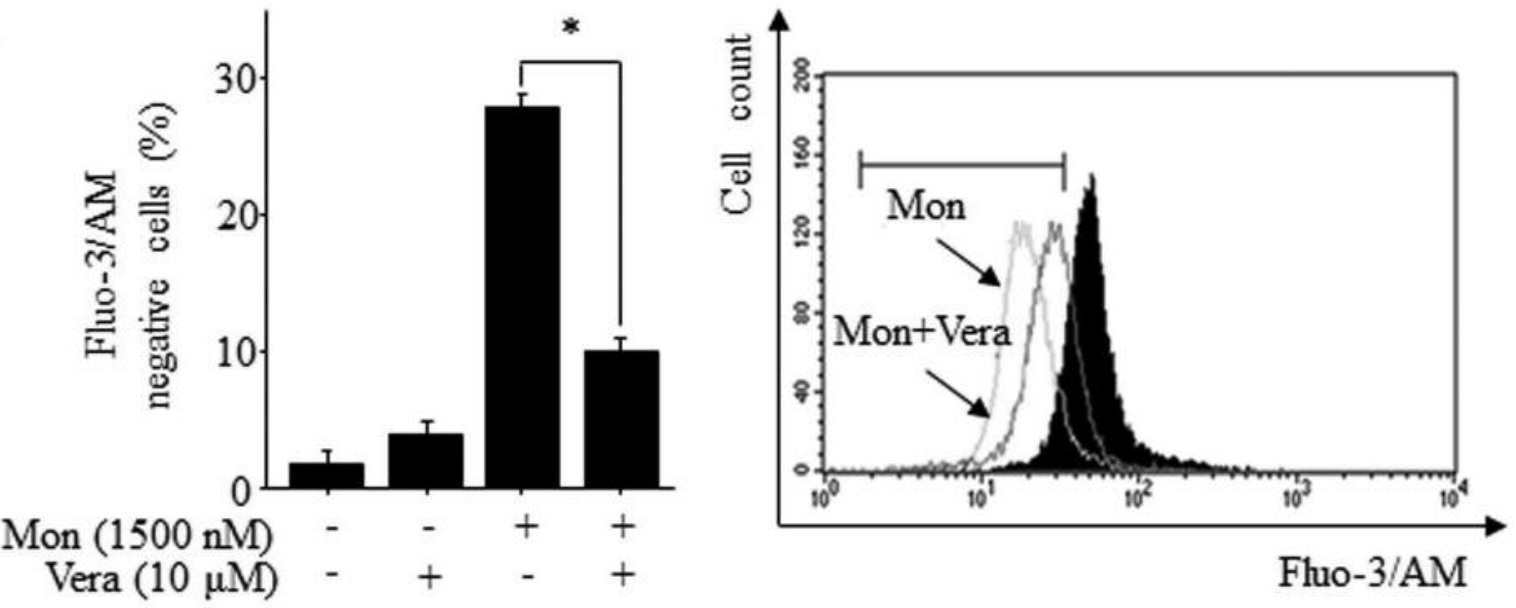

B

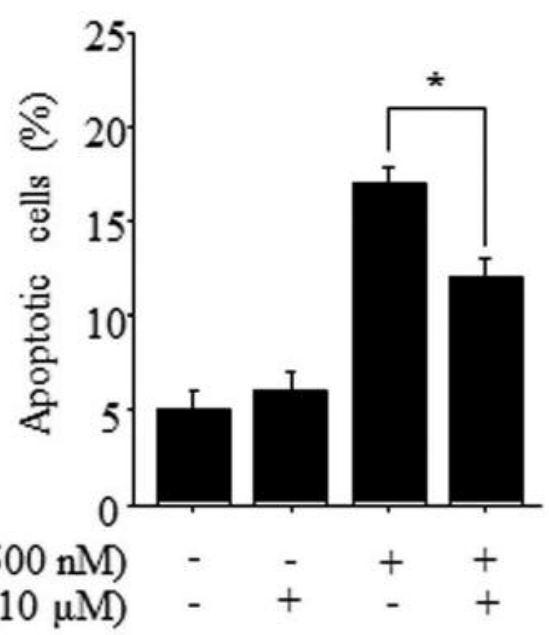

C

D

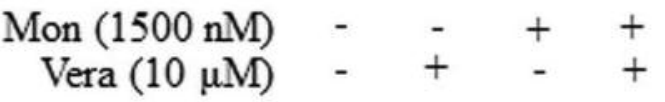

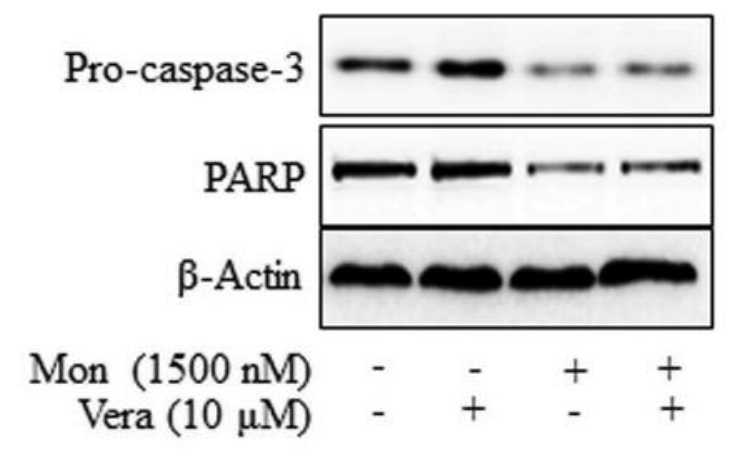

$\mathbf{E}$

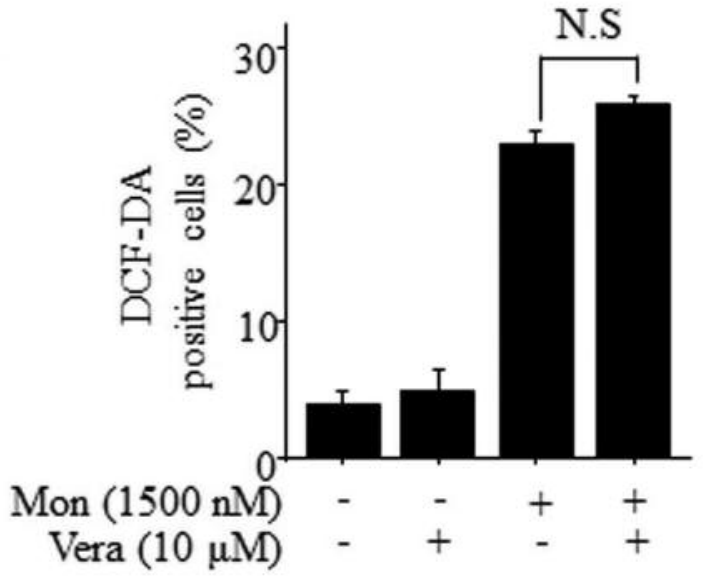

Figure 4. Monensin reduces the Ca $a^{2+}$ flux in PC-3 cells. A: Intracellular Ca ${ }^{2+}$ flux. B: Effects of $10 \mu M$ verapamil (Vera) on monensin-induced apoptosis. After annexin V/propidium iodide staining, apoptotic cells were analyzed by flow cytometry. C: Immunoblots of apoptosis-related proteins. Pro-caspase-3 and poly (ADP-ribose) polymerase (PARP) expression in total cell lysates were subjected to sodium dodecyl sulfate-polyacrylamide gel electrophoresis for western blot analysis. $\beta$-Actin was used as a loading control. D: Effects of $1 \mu M$ diphenyleneiodonium (DPI) on Ca ${ }^{2+}$ flux. E: Effects of $10 \mu \mathrm{M}$ verapamil (Vera) on reactive oxygen species generation. PC-3 cells were treated with 1,500 $\mathrm{nM}$ monensin for $24 \mathrm{~h}$ in the presence or absence of $10 \mu M$ verapamil (Vera). The Fluo-3/AM and DCFH-DA fluorescence intensity was detected by flow cytometry. Data are the mean $\pm S D\left(n=3\right.$ in each group). ${ }^{*} p<0.05$ vs. the control. N.S.: Non-significant difference. 


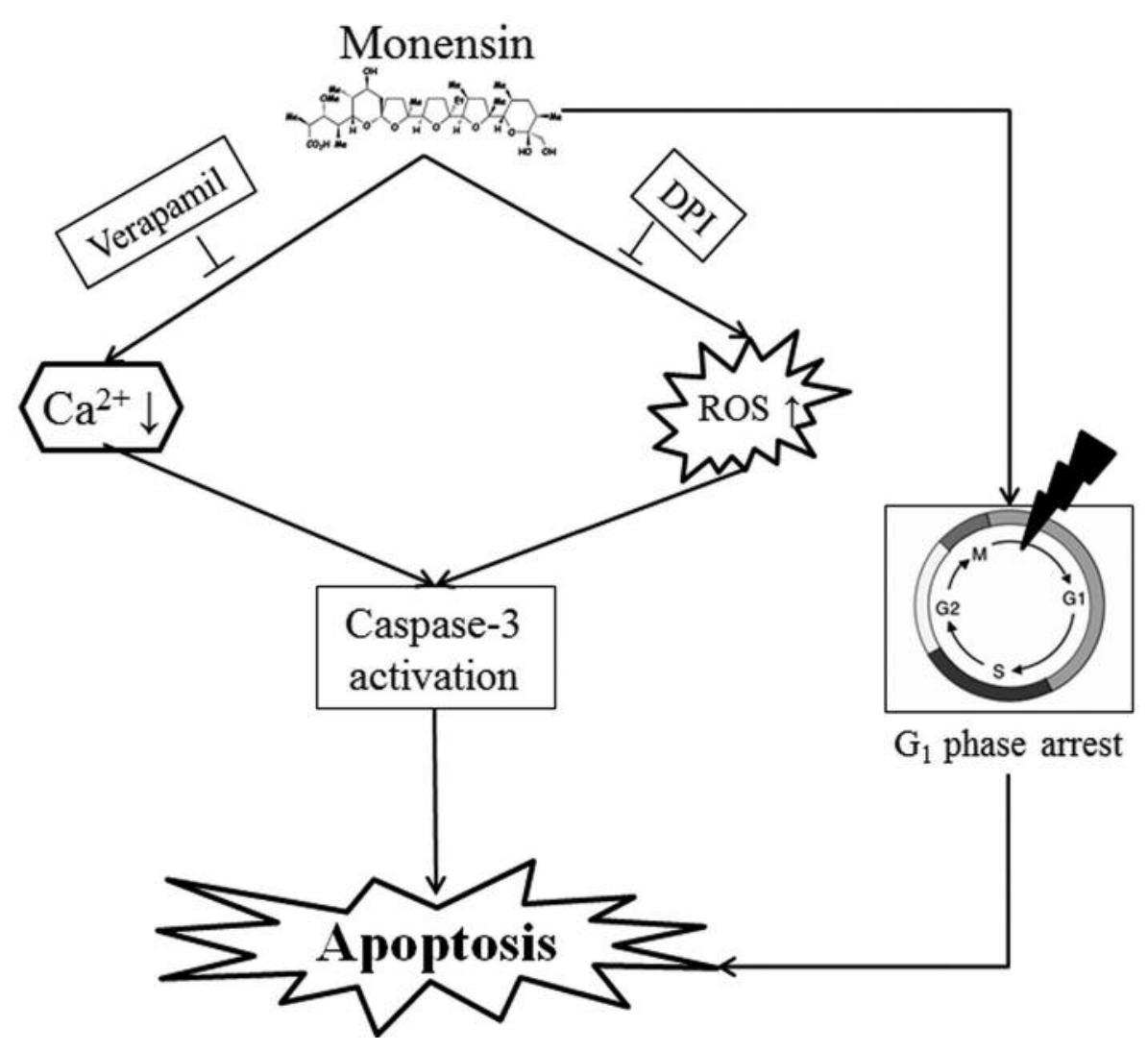

Figure 5. Schematic drawing representing possible mechanisms underlying monensin-induced apoptosis of prostate cancer PC-3 cells. ROS: Reactive oxygen species; DPI: diphenyleneiodonium.

accompanied by caspase-3 activation and PARP cleavage, suggesting a sequence of events associated with the induction of apoptosis in PC-3 cells. DPI, as an ROS inhibitor, abolished the effect of ROS induction (19). On the basis of these observations, we concluded that ROS acts as an upper signaling event to initiate the apoptotic pathway.

It has been extensively reported that ROS are also responsible for mitochondrial $\mathrm{Ca}^{2+}$ overload and endoplasmic reticulum stress by depletion of $\mathrm{Ca}^{2+}(29)$. Therefore, we assessed intracellular $\mathrm{Ca}^{2+}$ in PC-3 cells as an apoptotic marker after treatment of monensin. The exposure of $\mathrm{PC}-3$ cells to monensin led to a decrease of the intracellular $\mathrm{Ca}^{2+}$ level. Pre-treatment of PC-3 cells with verapamil, as calcium channel blocker, reversed the intracellular $\mathrm{Ca}^{2+}$ influx and reduced the apoptosis rate. Previously, we revealed the apoptotic pathway via ROS production, which causes dysfunction of mitochondria and disruption of $\mathrm{Ca}^{2+}$ homeostasis in PC-3 cells (10). In contrast to our previous report (10), the present study showed that DPI and verapamil did not affect the $\mathrm{Ca}^{2+}$ level and ROS production, respectively. These results suggest that changes of intracellular $\mathrm{Ca}^{2+}$ play a role in monensin-induced apoptosis through an ROS-independent pathway. In summary, monensin efficiently inhibited cell growth by inducing $G_{1}$-phase cellcycle arrest through regulation of cyclins and CDKs in human prostate cancer PC-3 cells. Monensin-induced apoptosis was mediated by ROS production and intracellular $\mathrm{Ca}^{2+}$ changes in PC-3 cells (Figure 5), evidenced by caspase-3 activation and PARP cleavage. In conclusion, this study will help establish the mechanism of ROS formation as well as calcium homeostasis by monesin in prostate cancer cells, which may have therapeutic implications.

\section{Acknowledgements}

This work was supported by the 2012 Specialization Project Research Grant funded by Pusan National University and by Basic Science Research Program through the National Research Foundation of Korea (NRF) funded by the Ministry of Education (2016R1D1A1B01009681).

\section{Conflicts of Interest}

Authors did not report any conflict of interest in regard to this study. 


\section{References}

1 Elmore S: Apoptosis: a review of programmed cell death. Toxicol Pathol 35: 495-516, 2007.

2 Hassan M, Watari H, AbuAlmaaty A, Ohba Y and Sakuragi N: Apoptosis and molecular targeting therapy in cancer. Biomed Res Int 2014: 150845, 2014

3 Kim SH, Kim KY, Yu SN, Seo YK, Chun SS, Yu HS and Ahn SC: Silibinin induces mitochondrial NOX4-mediated endoplasmic reticulum stress response and its subsequent apoptosis. BMC Cancer 16: 452, 2016.

4 Klaunig JE, Kamendulis LM and Hocevar BA: Oxidative stress and oxidative damage in carcinogenesis. Toxicol Pathol 38: 96109,2010

5 Liou GY and Storz P: Reactive oxygen species in cancer. Free Radic Res 44: 479-496, 2010

6 Panieri E and Santoro MM: ROS homeostasis and metabolism: a dangerous liason in cancer cells. Cell Death Dis 7: e2253, 2016.

7 Trachootham D, Lu W, Ogasawara MA, Nilsa RD and Huang P: Redox regulation of cell survival. Antioxid Redox Signal 10: 1343-1374, 2008.

8 Pinton P, Giorgi C, Siviero R, Zecchini E and Rizzuto R: Calcium and apoptosis: ER-mitochondria $\mathrm{Ca}^{2+}$ transfer in the control of apoptosis. Oncogene 27: 6407-6418, 2008.

9 Fulda S, Gorman AM, Hori O and Samali A: Cellular stress responses: cell survival and cell death. Int J Cell Biol 2010: 214074, 2010.

10 Kim KY, Cho HJ, Yu SN, Kim SH, Yu HS, Park YM, Mirkheshti N, Kim SY, Song CS, Chatterjee B and Ahn SC: Interplay of reactive oxygen species, intracellular $\mathrm{Ca}^{2+}$ and mitochondrial homeostasis in the apoptosis of prostate cancer cells by deoxypodophyllotoxin. J Cell Biochem 114: 11241134, 2013.

11 Lee W, Kim KY, Yu SN, Kim SH, Chun SS, Ji JH, Yu HS and Ahn SC: Pipernonaline from Piper longum Linn. induces ROSmediated apoptosis in human prostate cancer PC-3 cells. Biochem Biophys Res Commun 430: 406-412, 2013.

12 Nachliel E, Finkelstein Y and Gutman M: The mechanism of monensin-mediated cation exchange based on real time measurements. Biochim Biophys Acta 1285: 131-145, 1996.

13 Huczynski A: Polyether ionophores-promising bioactive molecules for cancer therapy. Bioorg Med Chem Lett 22: 7002 7010, 2012.

14 Kim KY, Yu SN, Lee SY, Chun SS, Choi YL, Park YM, Song CS, Chatterjee B and Ahn SC: Salinomycin-induced apoptosis of human prostate cancer cells due to accumulated reactive oxygen species and mitochondrial membrane depolarization. Biochem Biophys Res Commun 413: 80-86, 2011.

15 Miller SC, Huang R, Sakamuru S, Shukla SJ, Attene-Ramos MS, Shinn P, Van Leer D, Leister W, Austin CP and Xia M: Identification of known drugs that act as inhibitors of NFkappaB signaling and their mechanism of action. Biochem Pharmacol 79: 1272-1280, 2010.

16 Yoon MJ, Kang YJ, Kim IY, Kim EH, Lee JA, Lim JH, Kwon TK and Choi KS: Monensin, a polyether ionophore antibiotic, overcomes TRAIL resistance in glioma cells via endoplasmic reticulum stress, DR5 upregulation and c-FLIP downregulation. Carcinogenesis 34: 1918-1928, 2013.
17 Kim KY, Kim SH, Yu SN, Park SK, Choi HD, Yu HS, Ji JH, Seo YK and Ahn SC: Salinomycin enhances doxorubicin-induced cytotoxicity in multidrug-resistant MCF-7/MDR human breast cancer cells via decreased efflux of doxorubicin. Mol Med Rep 12: 1898-1904, 2015.

18 Gupta PB, Onder TT, Jiang G, Tao K, Kuperwasser C, Weinberg RA and Lander ES: Identification of selective inhibitors of cancer stem cells by high-throughput screening. Cell 138: 645$659,2009$.

19 Song H, Han IY, Kim Y, Kim YH, Choi IW, Seo SK, Jung SY, Park S and Kang MS: The NADPH oxidase inhibitor DPI can abolish hypoxia-induced apoptosis of human kidney proximal tubular epithelial cells through $\mathrm{Bcl} 2$ up-regulation via ERK activation without ROS reduction. Life Sci 126: 69-75, 2015.

20 Kanno T, Sato EE, Muranaka S, Fujita H, Fujiwara T, Utsumi T, Inoue $\mathrm{M}$ and Utsumi $\mathrm{K}$ : Oxidative stress underlies the mechanism for $\mathrm{Ca}(2+)$-induced permeability transition of mitochondria. Free Radic Res 38: 27-35, 2004.

21 Canzoniero LM, Babcock DJ, Gottron FJ, Grabb MC, Manzerra P, Snider BJ and Choi DW: Raising intracellular calcium attenuates neuronal apoptosis triggered by staurosporine or oxygen-glucose deprivation in the presence of glutamate receptor blockade. Neurobiol Dis 15: 520-528, 2004.

22 Chapman HD, Jeffers TK and Williams RB: Forty years of monensin for the control of coccidiosis in poultry. Poult Sci 89: 1788-1801, 2010.

23 Kim KY, Seo YK, Yu SN, Kim SH, Suh PG, Ji JH, Yu HS, Park YM and Ahn SC: Gene Expression Profiling from a Prostate Cancer PC-3 Cell Line Treated with Salinomycin Predicts Cell Cycle Arrest and Endoplasmic Reticulum Stress. J Cancer Sci Ther 5: 23-30, 2013.

24 Fink SL and Cookson BT: Apoptosis, pyroptosis and necrosis: mechanistic description of dead and dying eukaryotic cells. Infect Immun 73: 1907-1916, 2005.

25 Taatjes DJ, Sobel BE and Budd RC: Morphological and cytochemical determination of cell death by apoptosis. Histochem Cell Biol 129: 33-43, 2008.

26 Kalogeris T, Bao Y and Korthuis RJ: Mitochondrial reactive oxygen species: a double-edged sword in ischemia/reperfusion vs. preconditioning. Redox Biol 2: 702-714, 2014.

27 Niizuma K, Yoshioka H, Chen H, Kim GS, Jung JE, Katsu M, Okami N and Chan PH: Mitochondrial and apoptotic neuronal death signaling pathways in cerebral ischemia. Biochim Biophys Acta 1802: 92-99, 2010

28 Moustafa MH, Sharma RK, Thornton J, Mascha E, Abdel-Hafez MA, Thomas AJ Jr. and Agarwal A: Relationship between ROS production, apoptosis and DNA denaturation in spermatozoa from patients examined for infertility. Hum Reprod 19: 129-138, 2004.

29 Bhandary B, Marahatta A, Kim HR and Chae HJ: An involvement of oxidative stress in endoplasmic reticulum stress and its associated diseases. Int J Mol Sci 14: 434-456, 2012.

Received August 8, 2016

Revised September 7, 2016 Accepted September 12, 2016 